\title{
INVENTERISASI HUTAN DENGAN TEKNIK PENGINDERAAN JAUH MULTITINGKAT
}

\author{
oleh : Sugibarto Budi S.
}

\begin{abstract}
$\overline{\text { ABSTRACT }}$
Forest has important role in the sustainable development. Not only do forest has economic function, but it has ecological function as well. Forest management must be done continually to keep it from devastation. It is impossible to do this without good inventory. Forest inventory can be done through terrestrial survey or remote sensing technique, or both the two. By using terrestrial survey, we get detailed and accurate information. But, we need much time, cost, and many surveyor. By using remote sensing technique that is combined by terrestrial survey, we will get complete data relatively and lower time, cost and surveyor than terrestrial survey only.
\end{abstract}

\section{INTISARI}

Hutan mempunyai peranan yang sangat penting dalam pembangunan berkelanjutan. Hutan tidak hanya mempunyai fungsi ekonomi tetapi juga mempunyai fungsi ekologi. Pengelolaan butan barus dilaksanakan secara berkesinambungan agar terjaga dari kehancuran. Hal ini tak mungkin dapat dilaksanakan tanpa adanya kegiatan inventarisasi. Inventarisasi butan dapat dilakukan melalui survai darat maupun dengan menggunakan teknik penginderaan jaub, atau keduanya. Dengan survai darat akan diperoleb infomasi yang akurat namun dalam pelaksanaanya memerlukan banyak waktu, biaya, dan tenaga. Dengan menggunakan teknik penginderaan jaub yang dibantu dengan survai darat akan diperoleb data yang relatif lengkap dengan waktu, tenaga dan beaya yang lebih rendah.

\section{PENDAHULUAN}

Hutan merupakan salah satu sumber daya alam yang penting dan mempunyai peranan yang sangat besar dalam pembangunan nasional, yakni pembangunan yang berkelanjutan yang berwawasan lingkungan. Sebagai sumber daya alam, hutan memberikan sumbangan yang besar dalam memasok devisa non migas. Disamping itu, hutan juga mempunyai fungsi ekologis, yakni menghisap karbon dari udara, menyaring udara kotor akibat pencemaran kendaraan bermotor dan pabrik ( KLH, 1990).

Hutan di Indonesia diperkirakan mengalami penyusutan pada laju 15.000 - $20.000 \mathrm{Ha} /$ tahun. Luas hutan cenderung mengalami penyusutan sebagai akibat perubahan penggunaan lahan dari hutan ke pegunungan lain (permukiman, perindustrian, fasilitas perkotaan, dan sebagainya). Penyusutan ini seiring dengan peningkatan jumlah penduduk dan kegiatan pembangunan. Sementara itu hutan mangrove yang berfungsi seebagai tempat pengendapan lumpur dari bahan pencemaran, pelindung 
pantai dari abrasi serta penahanan intrusi air laut telah mengalami penciutan sampai $31 \%$ dari 4.29 juta hektar hutan mangrove di indonesia (Aca Sugandhy, 1993). Sebagai gambaran yang cukup lengkap mengenai laju penggundulan hutan di negara tropis disajikan pads tabel 1.

Penyusutan luas hutan yang terus berlanjut akan mengakibatkan kemerosotan lingkungan. Oleh karena itu, pelestarian hutan diperlukan sebagai upaya perlindungan lingkungan hidup, pengembangan pariwisata, serta pengembangan pendidikan dan ilmu pengetahuan. Sejalan dengan hal itu perlu dilaksanakan inventarisasi keanekaragaman sumber daya alam hayati dan ekosistemnya di kawasan kawasan hutan tersebut (Aca Sugandhy, 1993 ).

\section{Inventarisasi Hutan}

Inventarisasi hutan dapat diartikan sebagai kegiatan untuk menguraikan kuantitas dan kualitas pohon - pohon hutan serta berbagai karakteristik areal tanah tempat tumbuhnya ( Husch, 1987). Menurutnya, inventarisasi hutan yang lengkap di pandang dari segi penaksiran kayu harus berisi deskripsi areal berhutan serta pemilikannya; penaksiran volume pohon yang masih berdiri; penaksiran tambah tumbuh dan keluaran hasilnya.

Inventarisasi hutan dilakukan untuk berbagai tujuan, yang satu dengan yang lain berbeda, terutama pada pe- nekanannya. Husc ( 1987 ) mencontohkan bahwa inventarisasi pemilikan hutan swasta barangkali memerlukan informasi terinci mengenai hutan setiap spesies, kelas ukuran, lokasi tegakan yang tepat, fasilitas sarana angkutan. Sedangkan inventarisasi untuk menyiapkan rencana penebangan tidak memerlukan informasi tersebut, tetapi lebih menekankan pada topografi, pola drainase, dan sistem transpotasi, yang kesemuanya ini akan digunakan dalam menggambarkan skema pengeluaran kayu. Ia juga memberikan gambaran tentang prioritas dalam tujuan inventarisasi hutan sepeti disajikan pada tabel 2.

Inventarisasi hutan nasional memerlukan taksiran umum atas seluruh elemen inventarisasi hutan. Inventarisasi ini perlu menyajikan informasi penting untuk penyusunan perumusan nasional tentang pengembangan dan pemanfaatan hutan. Data yang perlu dalam inventarisasi ini lokasi, luas, klasifikasi terinci atas areal hutan beserta taksiran volume tegakan pada kawasan yang luas.

Inventarisasi untuk rencana kerja perlu menampung informasi terinci. Taksiran - taksiran volume menurut spesies diperlukan dari masing - masing tegakan dalam hutan. Disamping itu diperlukan juga data mengenai kelas tapak, taksiran rinci mengenai luas areal, 
LAJU PENGGUNDULAN HUTAN DI NEGARA TROPIS, TAHUN 1981 - 1985

TABEL 1

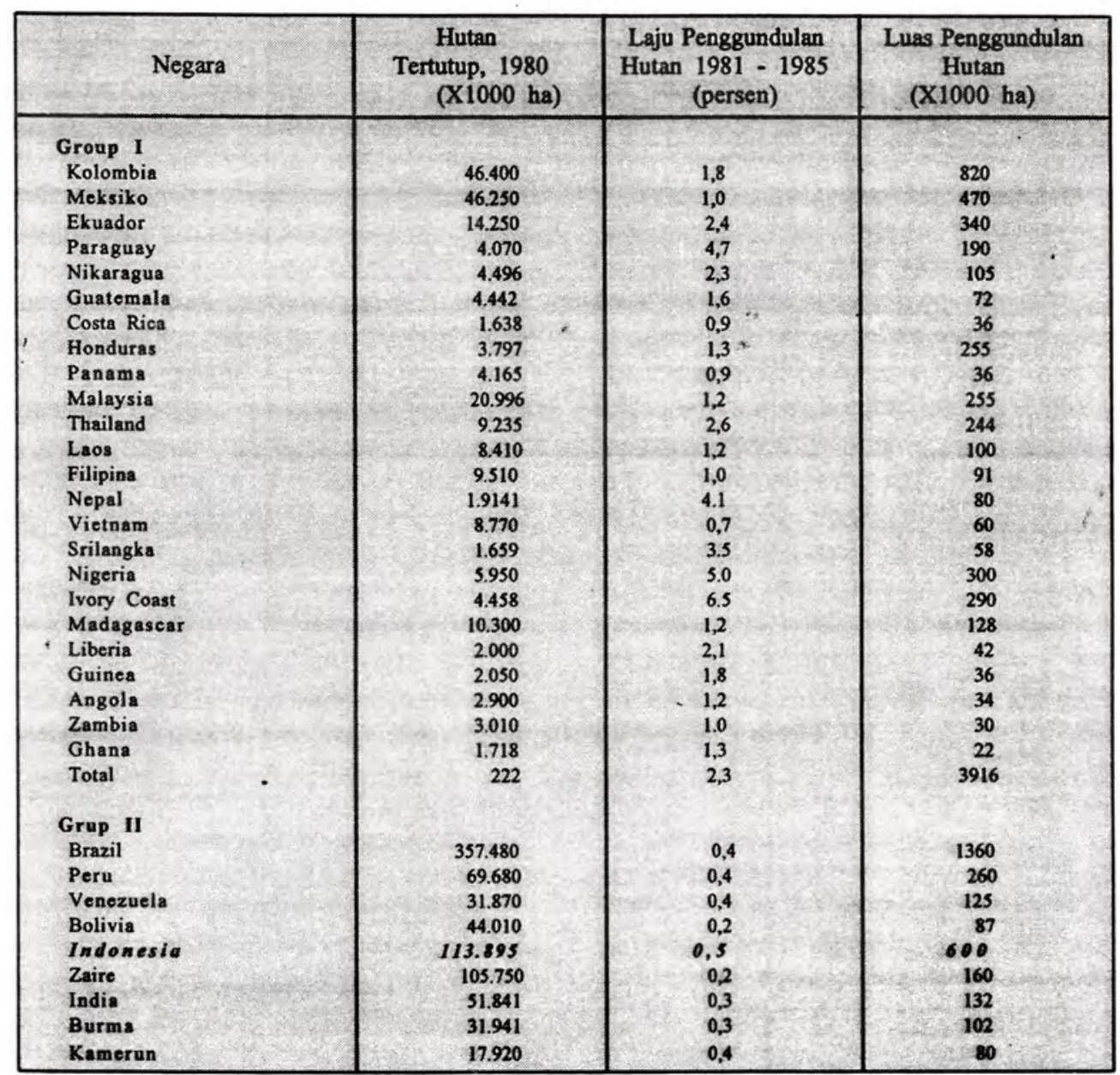

Forum Geografi No. 12 Th. VII / J u 1 i 1993 
LAJU PENGGUNDULAN HUT AN DI NEGARA TROPIS, TAHUN 1981 - 1985

TABEL 1 (-lanjutan )

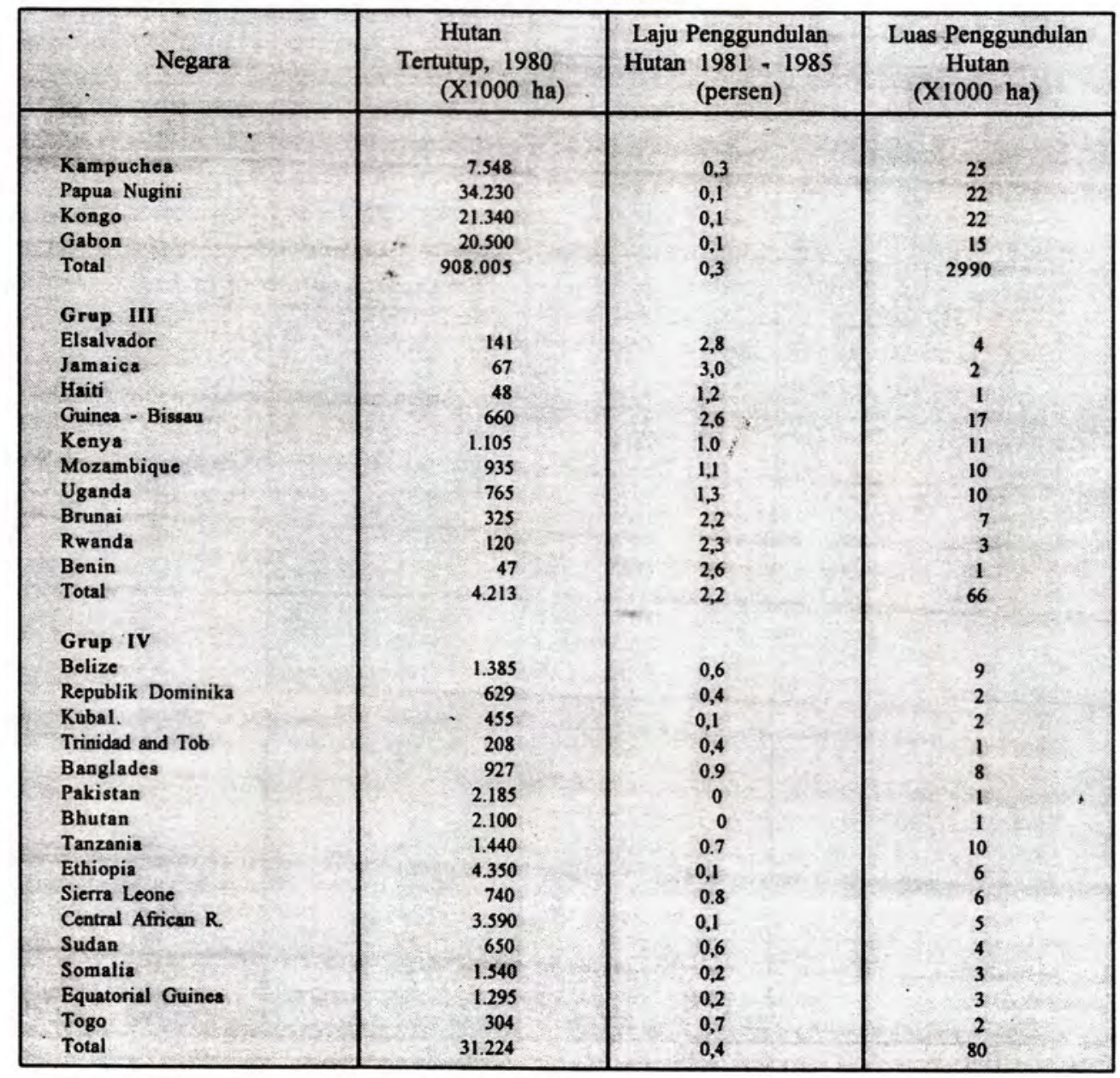

Keterangan

Grup I = laju penggundulan lebih tinggi daripada laju rata-rata dan luas yang terpengaruhi besar

Grup II = laju relatif rendah namun luas yang terpengaruhi besar.

Grup III = laju tinggi dan sisa hutan kecil

Grup IV = laju rendah sampai medium dan luas hutan yang terpengaruhi kecil

Sumber : World Resourrce Institute, 1988 dalam Kantor Menteri KLH, 1990 
informasi umum kondisi topografi, pola pemilikan dan fasilitas transpotasi.

Survei pengenalan hutan dirancang untuk menyediakan keterangan pendahuluan mengenai lokasi dan luas arealnya. Data mengenai lokasi, luas areal, dan kelas - kelas hutan secara kasar diperlukan dalam survei ini. Sedang survei untuk rencana pembalakan menampung keterangan yang penting untuk membuat program pemungutan hasil kayu. Informasi yang diperlukan menyangkut volume kayu berdasarkan spesies, ukuran dan kualitas, lokasi dan keterbukaan wilayah.

\section{Pelaksanaan Inventarisasi}

Dalam pelaksanaan inventarisasi hutan, masalah waktu, dana, dan tenaga adalah vital, dan pada banyaknya kasus hạl ini menjadi aspek pengendali perencanaan. Masalah ini tidak timbul begitu saja tetapi memasuki seluruh rangkaian kegiatan. Untuk itu perlu disusun suatu metode yang cocok sesuai dengan tujuan inventarisasi. Metode tersebut harus dirancang dengan melibatkan elemen-elemenn inventarisasi hutan seperti: areal, kuantitas dan karakteristik kayu, tambah-tambuh dan keluaran hasil (Husch, 1987). Informasi tersebut dapat diperoleh melalui pengukuran lapangan, teknik penginderaan jauh, atau kedua-duanya.

Inventarisasi hutan secara terestris memang menghasilkan informasi rinci serta ketelitian yang sangat tinggi, tetapi cara ini memerlukan waktu, tenaga, dann beaya yang sangat besar pula. Hanya dengan teknik penginderaan jauhpun, hasilnya tidak memuaskan. Cara yang terbaik adalah dengan menggabungkan keduanya.

\section{Penginderaan Jauh Multitingkat}

Penginderaan jauh dengan teknik multitiingkat yaitu penghinderaan jauh yang menggunakan wahana dengan ketinggian terbang di atas muka bumi dan atau tinggi orbit yang berbeda (Sutanto, 1986). Secara skematik konsep multi tingkat disajikan pada gambar 1 .

Pada gambar 1 di atas menunjukkan bahwa pada ketinggian tingkat I digunakan citra satelit dengann daerah liputannya paling luas. Sebagai contoh tiap lembar citra satelit Landsat meliput daerah seluas $185 \mathrm{~km} \mathrm{X} 185 \mathrm{~km}$ atau $34.225 \mathrm{~km}^{2}$ (Lillesand dan Kiefer, 1987). Karena liputannya luas ia hanya menyajikan informasi yang kurang lengkap. Kerinciannya dibuat dengan melakukan interpretasi foto udara bagi beberapa daerah sampel yang dipandang dapat mewakili keseluruhan daerah. Disamping sebagai daerah sampel, foto udara juga dipandang sebagai uji antara, yakni antara interpretasi citra satelit dan uji lapangan yang merupakan satu rangkaian dalam pekerjaan inter-pretasi. Berdasarkan pola hubungan ujud yang sama baik pada citra satelit maupun foto udara yang telah diuji kebenarannya di lapangan, kemudian dilakukan ekstrapolasi hasil interpretasi daerah sampel tersebut bagi seluruh daerah penelitian (Sutanto, 1986). Hasil yang diperoleh dengan cara multitingkat ini berupa informasi yang lebih rinci bagi daerah yang luas.

\section{Tahap Inventarisasi Hutan Dengan Teknik Multitingkat}

Tahap pertama yang dilakukan dalam inventarisasi hutan adalah interpretasi citra satelit, misalnya satlit 
TABEL2 PENEKANAN RELATIF ELEMEN-ELEMEN INVENTARISASI HUTAN

\begin{tabular}{|c|c|c|c|c|c|c|c|c|}
\hline \multirow{2}{*}{$\begin{array}{c}\text { Contoh } \\
\text { inventarisasi } \\
\text { hutan }\end{array}$} & \multicolumn{4}{|c|}{ Areal hutan } & \multirow{2}{*}{$\begin{array}{c}\text { Penaksiran } \\
\text { volume atau } \\
\text { parameter } \\
\text { lain }\end{array}$} & \multirow{2}{*}{$\begin{array}{c}\text { Penaksiran } \\
\text { tambah- } \\
\text { tumbuh }\end{array}$} & \multirow{2}{*}{$\begin{array}{c}\text { Penaksiran } \\
\text { keluaran } \\
\text { hasil }\end{array}$} & \multirow{2}{*}{$\begin{array}{c}\text { Informasi lain } \\
\text { untuk rekreasi, } \\
\text { daerah aliran. } \\
\text { tataguna lahan } \\
\text { lain yang mung- } \\
\text { kin, satwa liar } \\
\text { dan lain-lain }\end{array}$} \\
\hline & $\begin{array}{c}\text { Taksiran } \\
\text { luas }\end{array}$ & $\begin{array}{l}\text { Deskripsi } \\
\text { topografi }\end{array}$ & $\begin{array}{l}\text { Pola } \\
\text { Pemi } \\
\text { likan }\end{array}$ & $\begin{array}{l}\text { Keterbukaan } \\
\text { dan fasilitas } \\
\text { transportasi }\end{array}$ & & & & \\
\hline $\begin{array}{l}\text { Inventarisasi hu- } \\
\text { tan nasional .... }\end{array}$ & II & II & II & II & II & II & II & II \\
\hline $\begin{array}{l}\text { Survei rencana } \\
\text { kerja .... }\end{array}$ & I & II & II & II & I & I & I & II \\
\hline $\begin{array}{l}\text { Survei pengenalan } \\
\text { hutan .... }\end{array}$ & II & III & III & $\begin{array}{c}\text { II atau } \\
\text { III }\end{array}$ & $\begin{array}{l}\text { II atau } \\
\text { III }\end{array}$ & III & III & II \\
\hline $\begin{array}{l}\text { Survei rencana } \\
\text { tebangan .... }\end{array}$ & II & I & III & I & I & III & III & III \\
\hline $\begin{array}{l}\text { Informasi dasar } \\
\text { untuk studi kela- } \\
\text { yakan industri } \\
\text { kehutanan ..... }\end{array}$ & II & II & I & I & I & I & I & II \\
\hline $\begin{array}{l}\text { Data dasar untuk } \\
\text { penilaian tegakan }\end{array}$ & I & II & III & I & I & III & III & III \\
\hline $\begin{array}{l}\text { Studi tataguna } \\
\text { lahan }\end{array}$ & I & I & I & I & II & II & III & I \\
\hline Studi rekreasi & II & II & I & I & III & III & III & I \\
\hline $\begin{array}{l}\text { Studi daerah } \\
\text { aliran .... }\end{array}$ & I & I & II & II & II & II & II & I \\
\hline
\end{tabular}

umum

III - ditekankan sedikit atau dapat ditiadakan.

Sumber : Husch, 1987 


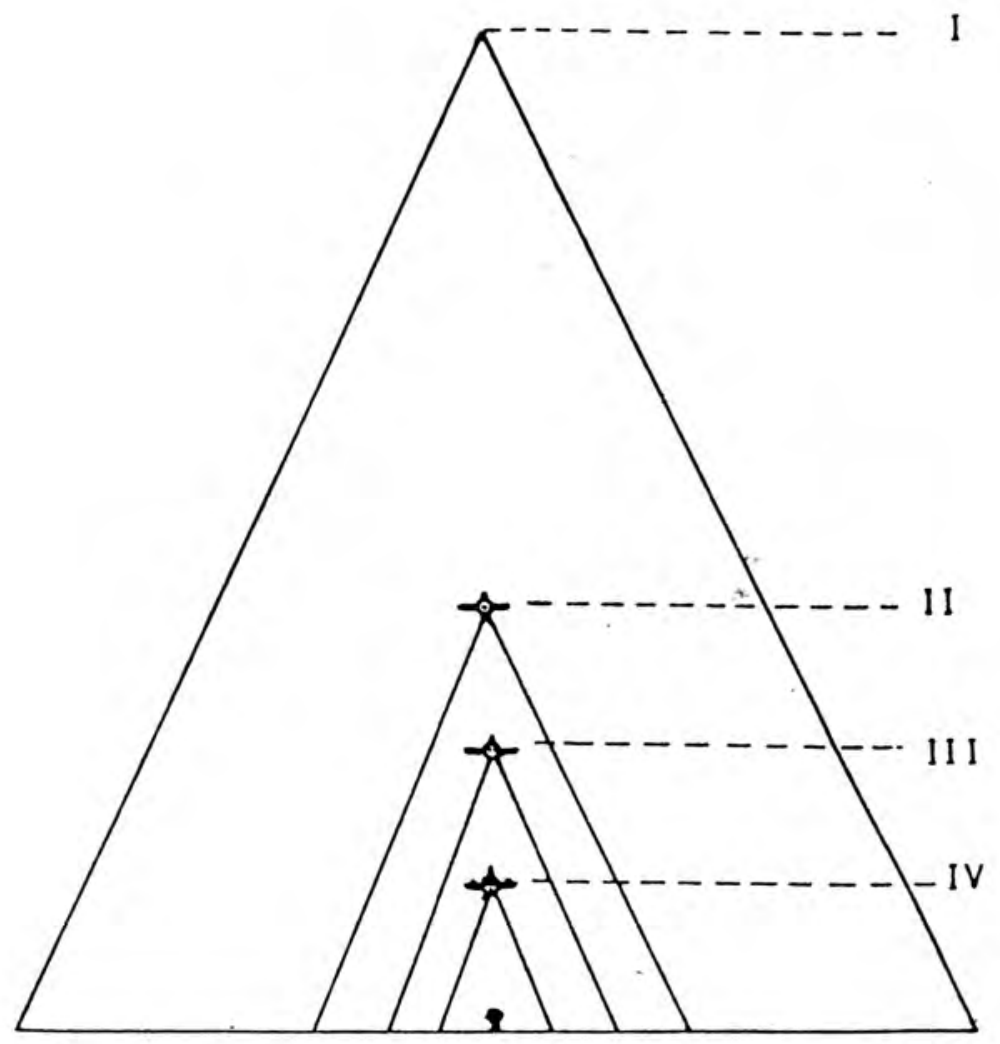

Gambar1 KONSEPMULTITINGKAT

I : Satelit dengan orbit $(200-36.000) \mathrm{km}$

II : pesawat yang terbang tinggi $(>15 \mathrm{~km})$

III : pesawat yang terbang sedang $(9-15) \mathrm{km}$

IV : pesawat yang terbang rendah $(<9 \mathrm{~km})$

Landsat. Dalam inventarisasi ini citra satelit digunakan untuk klasifikasi penutup lahan secara global.

Tahap kedua berupa interpretasi foto udara skala kecil, yakni skala lebih kecil dari 1: 30.000 (sabinns Jr, 1978 dalam Sutanto, 1986). Interpretasi dilakukan pada daerah-daerah sampel yang dianggap dapat mewakili keseluruhan wilayah yang dikaji. hasil dari interpretasi pada foto udara skala kecil ini berupa stratifikasi hutan pada tingkat tinjau, informasi penutup lahan serta penafsiran luas secara kasar.

Tahap ketiga berupa interpretasi foto udara skala sedang, yakni skala 1:20.00 - 1: 30.000 atau skala besar, yakni skala 1: 10.000 (Sabins. Jr. 1978 dalam sutanto, 1986). Husch (1987) menyarankan penggunaan foto udara skala 1: 15.000 sampai skala 1: 20.000 . Menurutnya pada skala tersebut paling umum untuk tujuan kehutanan, karena mewakili komposisi terbaik antara 
beaya rendah dan interpretasi foto udara yang cukup memadai. Data yang diperoleh dari interpretasi paa skala ini adalah tinggi pohon, diameter tajuk, dan kerapatan tegakan, serta jenis pohon.

Menurut Paine (1981), ada beberapa data dalam kegiatan inventarisasi hutan yang langsung dapat diukur pada foto udara, tetapi ada pula data yang tidak dapat secara langsung diukur pada foto udara. Data yang langsung dapat diukur pada foto udara meliputi: tegakan total atau tinggi pohon, diamter tajuk yang tampak, tingkat persediaan (penghitungan tajuk secara individu, persen penutup tajuk), panjang dan diameter gelondongan yang mengapung di kolam. Sedangkan data yang tidak dapat diukur langsung pada foto udara dilakukan dengan teknik statistik yang menggunakan karakteristik pohon atau tegakan yang dapat diukur langsung. Beberapa dari data tersebut meliputi: diameter batang setinggi dada, kelas bentuk, indeks lokasi, pertumbuhan, umur, volume (masing-masing pohon, tegakan per acre), dan luas bidang dasar per acre.

Tahap keempat berupa pengujian medan hasil interpretasi. Uji medan perlu dilakukan untuk mencocokkan hasil interpretasi dengan keadaan sebenarnya di lapangan serta untuk mengetahui apakah tingkat ketelitian interpretasi tersebut dalam batas yang

\section{Daftar Pustaka}

diperbolehkan.

Tahap terakhir berupa interpretasi ulang. Pada tahap ini dilakukan pembetulan kesalahan hasil interpretasi sebelumnya. Disamping itu dilakukan juga ekstrapolasi hasil interpretasi foto udara yang telah dikoreksi, pada hasil interpretasi citra satelit.

\section{Kesimpulan}

Mengingat begitu pentingnya hutan bagi kehidupan manusia, yakni disamping mempunyai fungsi ekonomi juga mempunyai fungsi ekologis, maka pengelolaan hutan perlu dilaksanakan secara seksama dan terus menerus. Pengelolaan hutan yang baik tidak mungkin tercapai tanpa adanya data inventarisasi yang baik.

Inventarisasi hutan dapat dilakukan dengan cara terestris aau melalui teknik penginderaan jauh, atau gabungan keduanya. Dengan cara terestris informasi yang diperoleh sangat lengkap dengan tingkat ketelitianyang sangat tinggi. Tetapi cara ini akan memakan waktu tenaga, dan beaya yang besar. lebih-lebih bagi negara yang wilayahnya luas seperti Indonesia, kendala ini akan sangat terasa. Dengan teknik penginderaan jauh multitingkat yang disertai uji medan, akan diperoleh informasi hutan yang relatif lengkap dengan ketelitian yang cukup memadai, serta beaya, waktu, dan tenaga yang jauh lebih kecil bila dibandingkan dengan cara terestris.

Aca Sugandhy. 1993. Kebjiksanaan Pembangunan Lingkungan Hidup Pada PJPT II Dan Upaya-Upaya Konservasi Hutan, Tanah Dan Air. Seminar Nasional Konservasi

Hutan, Tanah dan Air. Yogyakarta. Pusat Penelitian Lingkungan Hidup UGM.

B. Husch. 1987. Perencanaan Inventarisasi Hutan. Terjemahan. Jakarta: UI Press.

David P. Paine. 1981. Aerial Photograpy and Image Interpretation for Resource Management. New York: John Wiley and Sons.

Kantor Menteri KLH. 1990. Kependudukan dan Lingkungan Hidup. Jakarta.

Sutanto. 1986. Penginderaan Jauh Jilid 1. Yogyakarta Gamma Press 